\title{
Gender differences in self-perception accuracy: The confidence gap and women leaders' underrepresentation in academia
}

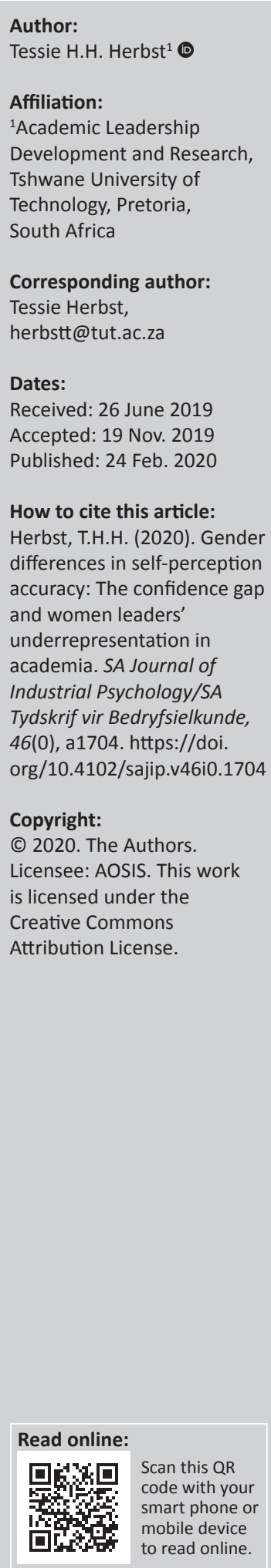

Orientation: The study reported here explores the preconceived notion of women's missing agency - characterised by a lack of confidence - as an explanation for their continued underrepresentation at senior leadership levels in higher education institutions (HEIs) in South Africa.

Research purpose: The study investigated gender differences in self-perception accuracy, defined as self-other agreement. The concept of confidence in this article refers to a high degree of self-perception accuracy defined as self-other rating agreement.

Motivation for the study: One of the reasons for the underrepresentation of women in senior leadership levels frequently cited in the literature is the relationship between self-confidence and effective leadership. This phenomenon has however not yet been researched in the context of South African HEIs.

Research approach/design and method: A quantitative, cross-sectional study of gender differences in self-perception accuracy using data collected from a 360-degree assessment intervention amongst the total population $(N=112)$ of academic managers in a HEI in South Africa was conducted. The realised sample consisted of 74 managers with an average of 9.5 raters per participant.

Main findings: The results revealed that significant gender differences with regard to self-perception accuracy emerged. This was in spite of the fact that male and female leaders were perceived to be equally effective by their raters.

Practical/managerial implications: The implications of women leaders' inaccurate self-perceptions on their career progression and the design of leadership development programmes aimed at improving gender disparity are discussed.

Contribution/value-add: This study contributes to scientific knowledge regarding the factors that contribute to the slow advancement of women to senior leadership positions in HEIs.

Keywords: self-confidence; gender; higher education; leadership; 360-degree feedback; self-perception accuracy

\section{Introduction}

Progress towards gender equity has been rapid in South African universities. However, disaggregated data reveal that, in general, women are clustered mainly within the lower ranks of higher education institutions (HEIs). Research by Moodly and Toni (2017) confirmed that in spite of progressive policies regarding gender equity in the South African higher education (HE) system, women are still not breaking the glass ceiling when it comes to accessing senior leadership positions. Bawa ${ }^{1}$ concurs by stating that 'it would be fair to say that the upper echelons of HE leadership are still very male-centred' (Naidu, 2018). Furthermore, it is concerning that in spite of the 2017 and 2018 appointments of women at two South African institutions (Nelson Mandela University and the University of Cape Town) in vice chancellor positions, women still constitute only about $19 \%$ of vice chancellors in South Africa (Toni \& Moodly, 2019). In addition, only $27.5 \%$ of the professors (from a total of 2218) are women (Naidu, 2018). Thus, women's underrepresentation at the higher academic ranks is in contrast to their visibility in larger numbers in the lower ranks of the academy (Toni \& Moodly, 2019). It is thus clear that universities continue to be gendered institutions (Acker, 2010; Kele \& Pieterson, 2015; Moodly \& Toni, 2017; Morley, 2013; Shepherd, 2017; Toni \& Moodly, 2019) and as stated by Kele and Pieterson (2015, p. 14) still 'unconsciously

1.Professor Ahmed Bawa is the chief executive officer of Universities South Africa (USAf), whose members comprise the heads of the country's 26 tertiary education institutions. 
gender biased'. Research by Burkinshaw and White (2017) confirmed that one of the main reasons for women's underrepresentation is the gendered power relations dynamics in universities that persistently preserve these entrenched inequalities. As a result, women find themselves in a gendered institutional culture with few senior women as role models (Howe-Walsh \& Sarah Turnbull, 2016). These patterns of greater gender disparity at senior levels are reflective of those in other parts of the world, including universities in developed countries (Burkinshaw \& White, 2017; Howe-Walsh \& Turnbull, 2016; Manfredi, 2017; Shepherd, 2017; Winchester \& Browning, 2015) as well as the corporate sector (World Economic Forum [WEF], 2017). From both an organisational and social justice perspective, the current state of affairs is problematic.

From the above discussion, it is clear that there may be genderspecific barriers to achieve equity in universities, which needs to be understood (Devar, 2017; Kele \& Pieterson, 2015; Moodly \& Toni, 2015; Moodly \& Toni, 2017; Morley, 2013). Various reasons for women's continued underrepresentation at senior leadership levels in $\mathrm{HE}$ are mentioned in the literature (Moodly \& Toni, 2017). One of the most significant reasons cited is the lack of fit between stereotype-based characteristics deemed necessary for effective leadership and women's distinctive characteristics and qualities (Hoyt \& Murphy, 2016). As a result, the entrenched masculine practices of universities are alienating women academics, as they favour masculine behaviours and values (Burkinshaw \& White, 2017; Moodly \& Toni, 2017). Research by Kele and Pieterson (2015) provided evidence that gender stereotypes and misconceptions about women's leadership ability act as barriers to the performance of senior women in HEIs. These biases towards women's abilities to lead are confirmed by Ragins, Townsend and Mattis (1998), who describe organisational cultures as inhospitable and exclusionary. This culture of exclusion manifests as male dominance, silencing of women's voices and male patterns of networking (Toni \& Moodly, 2019). These perceptual errors also result in women having less access to high-status colleagues with whom to network, which serves as an additional barrier for women's advancement (Stainback, Kleiner, \& Skaggs, 2016; Toni \& Moodly, 2019). These hostile cultures even cause some women to opt out of senior management as a self-preservation strategy - an attempt to avoid the 'cruel optimism' of aspiring for something, which they believe is a statistical improbability (Morley, 2014, p. 120). This belief that their senior leadership aspirations will most likely not realise has some empirical foundation (Business Women Association of South Africa, 2017; Kele \& Pieterson, 2015; Manfredi, Grisoni, Handley, Nestor, \& Cooke, 2014; Moodly \& Toni, 2017; Shepherd, 2017). Therefore, as stated by Burkinshaw and White (2017), a 'fixing the women' approach is unlikely to be efficient in redressing the current gender imbalance within university executive management teams.

Another reason for the under $\backslash$ representation of women in senior levels frequently cited in the literature is the relationship between self-confidence and effective leadership (Bear,
Cushenbery, London, \& Sherman, 2017; Kay \& Shipman, 2014; McCormick, 2001). The author acknowledges the multiplicity of factors that contribute to the slow advancement of women to senior leadership positions in HEIs. However, institutional cultures that are biased against women contribute to the perceived lack of confidence and the phenomenon of leadership deficit that the article attempts to address. As stated by Martin and Philips (2017), confidence drives the attainment of power and status, and signals competence. A lack of confidence therefore has definite implications for goal achievement and career success (Anderson \& Brion, 2010; Kay \& Shipman, 2014). As stated by Acker (2010), strategic agency is required if individuals are to prosper in the academia. Therefore, as mentioned by Kay and Shipman (2014), the reduction of the confidence gap is a prerequisite to eliminate the current gender inequality in senior levels. This article investigates the preconceived notion of women's missing agency - characterised by a lack of confidence - as an explanation for their continued underrepresentation. The article presents the findings of a 360-degree assessment intervention amongst 88 academic managers in a HEI in South Africa. These managers were rated by a total of 699 raters, which included their line managers, peers and subordinates.

\section{Literature review Defining confidence}

Carducci (2009, p. 516) defined self-confidence as 'an individual's self-assessment of his or her ability to be successful at a particular task'. The fact that women have lower expectations of success than men in many areas of achievement - which might be indicative of their tendency to underestimate themselves - is well established in the literature (Betsworth, 1999; Beyer, 1999; Kay \& Shipman, 2014; Meyerson, Sternbach, Zwischenberger, \& Bender, 2017). Selfconfidence refers to an individual's self-judgement of his or her capabilities and skills, or their perceived competence to deal successfully with the demands of a variety of situations (Shrauger \& Schohn, 1995). Bandura (1997) stated that perceived self-efficacy is concerned with people's beliefs in their capabilities to produce given attainments. Both theory as well as empirical findings indicate that general, trait selfefficacy (or self-confidence) influences an individual's estimate of his or her situation-specific self-efficacy (McCormick, 2001). In this article, the concept of confidence is grounded in Bandura's social cognitive theory (1997), which defined self-efficacy as one's task-specific self-confidence, that is, as in the case of this study, exercising leadership. Thus, the concept of confidence in this article refers to a high degree of self-perception accuracy defined as self-other rating agreement (SOA) (Yammarino \& Atwater, 1993) as assessed by a 360-degree questionnaire. As such, self-perception accuracy in this study is defined in line with the definition by Fleenor, Smither, Atwater, Braddy and Sturm (2010, p. 1005), as the 'degree of agreement between or congruence between a leader's self-ratings and the ratings of others, usually colleagues such as superiors, peers, and subordinates'. 


\section{The gender gap in leadership}

Kinnear and Ortlepp (2016, p. 2) stated that 'gender stereotyping remains at the heart of the challenge women experience in asserting alternative models of power'. Much of the literature on leadership often use 'masculine' leadership as the prototype (Booysen \& Nkomo, 2010; Burkinshaw \& White, 2017), and this belief is confirmed by numerous research studies that demonstrate that people link men with more of the traits that connote leadership (Eagly \& Carli, 2003). In a meta-analysis of 69 studies by Koenig, Eagly, Mitchell and Ristikari (2011), the overall 'masculinity' of leader stereotypes was confirmed. Characteristics associated with 'feminine' stereotype qualities, such as warmth and caring, were deemed irrelevant or even antithetical to managerial success. As a result, women must outperform men significantly to counteract gender stereotypes and biases and to be perceived as equally competent (Bear et al., 2017; Burkinshaw \& White, 2017; Lyness \& Heilman, 2006). This was confirmed in a study by Ragins et al. (1998, p. 29), which revealed that the most common strategy used by successful women executives was 'consistently exceeding performance expectations'.

Not complying with gender stereotypes will lead to punitive measures for women by means of a less favourable performance rating compared to men who withhold interpersonal warmth or altruistic behaviour (for a review, see Cuddy, Glick, \& Beniger, 2011; Heilman \& Okimoto, 2007; Williams \& Tiedens, 2015). Although women are held to a higher standard for prosocial behaviour, the opposite is true for assertive behaviour. Powerful, assertive behaviour displayed by women is more likely to be judged as overly aggressive in contrast to how similar behaviour in a man is perceived (Eagly \& Carli, 2003; Fox, 2013; Rudman, MossRacucin, Phelan, \& Nauts, 2012). Research by Williams and Tiedens (2015) provided irrefutable evidence that women are penalised more than men for dominant, assertive or selfpromoting behaviour and for expressing disagreement. Snyder (2014) echoed this view and stated that women are more likely than men to receive negative comments about their personality and are often told to tone down interpersonal behaviour. This also impacts on the way women network causing them to hold back for fear of appearing power hungry and self-promoting (Ely, Ibarra, \& Kolb, 2011; Heilman \& Parks-Stamm, 2007).

Furthermore, Bear et al. (2017) were of the opinion that women also receive less constructive objective feedback, which can assist them in improving their performance. In addition, women also receive less positive encouraging feedback than men which compounds women's disadvantage. This feedback deficiency has important implications for the development of women's identity as leaders and the advancement to a senior leadership position. As theory would suggest (Ely et al., 2011), constructing and internalising a leadership identity is central to the process of becoming a leader. These biases and stereotypical questions around women's confidence accumulate and interfere with their ability to accurately assess themselves, obstructing the identity work necessary to take up leadership roles. This inaccurate perception leads to their internalisation of inadequacy and lack of self-efficacy (Damaske, 2011; Stead, 2014). Thus, unlike men, women are expected to display communal behaviour, and not too much agentic behaviour, forcing them to adopt an androgynous, professional management style (i.e. not masculine or feminine) with which male managers and subordinates are comfortable. Should they not adopt an androgynous style, they pay a higher penalty than men (Kark, Waismel-Manor, \& Shamir, 2012; Rudman et al., 2012). This is a daunting challenge for women to not only exceed performance expectations as mentioned previously but also to find the appropriate non-threatening way to perform - a challenge their male counterparts are not faced with. Thus, there are serious constraints placed on women, as opposed to men, with regard to displaying assertive and confident behaviour.

\section{Gender and self-confidence or self-efficacy}

The gender gap in self-esteem is well documented in the literature (for a review see Gosling et al., 2016), with males reporting higher levels of self-esteem than women. While men in general tend to be over-confident (Barber \& Odean, 2001; Reuben, Rey-Biel, Sapienza, \& Zingales, 2012), women tend to be either accurate in their self-assessment or underestimate themselves (Beyer, 1999; Kay \& Shipman, 2014; Niederle \& Vesterlund, 2007). However, the evidence for gender differences in self-confidence is mixed (Croson \& Gneezy, 2009), with some studies finding that men are more confident in their performance than women (Beyer, 1999; Moshavi, Brown, \& Dodd, 2003; Niederle \& Vesterlund, 2007; Pulford \& Colman, 1997; Visser, Ashton, \& Vernon, 2008) and others finding no significant differences (Moore \& Healy, 2008). Research by Manfredi et al. (2014) revealed that women were more likely than men to cite a lack of confidence as an inhibiting factor on their career progression. Research by McGlone and Pfeister (2015) confirmed that stereotype-based concerns make women less fluent and cause them to use more tentative language. In contrast, research by Shephard (2017) found that men and women do not differ significantly in their aspirations to secure a more senior position. However, in an environment where women are still underrepresented in senior and executive positions - similar to the university where the study was conducted - gender differences in selfconfidence may emerge (Brutus, Fleenor, \& McCauley, 1999; Fleenor et al., 2010). More specifically, men might emerge as more confident than women when it comes to their own rating of their effectiveness regarding leadership behaviours (Bear et al., 2017).

\section{Research design Research approach}

A descriptive, cross-sectional and quantitative approach was used to gather data through the utilisation of a 360-degree survey questionnaire. The general approach of the study was, in the terminology of Mouton and Marais (1989), mainly 
descriptive (focussing on the classification of and interaction between variables) rather than explorative (investigating an entirely new phenomenon) or explanatory (focussing on cause and effect).

\section{Research method The design of the 360-degree instrument}

As stated by Damian and Pitts (2015), context is a critical component of successful leadership. Kets de Vries and Korotov (2010) stated that highly successful organisations have created contextualised leadership competency models to ensure that leaders are developed based on required skills and competencies to execute the strategy of the organisation. Therefore, the 360-degree survey questionnaire used in this study was aligned with a contextualised leadership competency model for the university. Structured interviews (with members of the executive management and executive deans) and focus groups (with nominated heads of departments [HODs] and academic section heads) were conducted to develop the contextualised leadership competence model for the university using the Saville card sort process $^{2}$ (Saville Consulting, 2015). Furthermore, a review of the literature as well as all documentation pertaining to the formulation of the new vision and strategy for the university was done. The competence model was validated and signed-off by the executive management committee of the university.

The survey questionnaire included the following four leadership competency clusters related to the contextualised leadership competence model: Cluster one: Collaborative change leadership; Cluster two: Strategy translation and innovation; Cluster three: Impactful relationship management; and Cluster four: Disciplined results orientation. In the questionnaire, each of the four competency clusters is explained in terms of a definition and between seven and 15 behavioural descriptors. The behavioural descriptors corresponding to each of the four leadership competence clusters resulted in a survey questionnaire comprising 44 statements. The 360-degree instrument was completely automated by means of an online system administered by an external service provider. Each leadership competence cluster was measured by between seven and 15 behavioural descriptors, rated on a 7-point Likert scale anchored by 'Seldom effective' (1) up to 'Always a strength' (7). Cronbach's alpha reliability coefficient test conducted on the survey instrument has confirmed the reliability of the instrument. All four leadership competence clusters are reliably testing their respective latent constructs as their respective Cronbach's alpha values are greater than 0.7 . The Cronbach's alpha values for each of the four competence clusters were as follows: Cluster one (0.7892), Cluster two (0.7406), Cluster three (0.8226) and Cluster four (0.8020).

2.Card sorting sessions enable an engaging and interactive experience for managers to share and compare views across a range of applications in a structured format. The Card share and compare views across a range of applications in a structured format. The Card
Deck presents the behaviours, abilities and global measures that Saville Consulting's Deck presents the behaviours, abilities and global measures that Saville Const
research has identified as key to drive workplace performance and potential.

\section{Participants}

The target group included all academic managers within the university (executive deans, assistant deans, HODs and academic section heads). This includes all academic managers in the seven faculties as well as within the Higher Education Development and Support (HEDS) unit. A total of 112 staff members $(N=112)$ fell within these categories. A total of 88 managers participated in the 360-degree feedback process. Of these, only 74 (29 women and 45 males) participants complied with the requirement of a minimum of three raters (excluding themselves). Of these participants, $9.6 \%$ (7) held an executive management position (six executive deans and one senior director), $15 \%$ (11) were assistant deans, $60.3 \%$ (45) were HODs and $15.1 \%$ (11) were section heads. A total of 694 raters participated providing ratings by managers, peers, subordinates and the person him or herself. This gave an average of 9.4 raters per participant.

\section{Ethical consideration}

Permission to conduct the 360-degree assessment intervention was obtained from the Senate Committee for Teaching and Learning. The intervention formed part a leadership capacity building project within the university. The test administrator assured the participants that their responses would be dealt with extreme confidentiality and that their anonymity would be safeguarded at all times. For purposes of confidentiality, all recognisable data have been carefully disguised or omitted. Permission to publish the data was obtained from the deputy vice chancellor, Teaching, Learning and Technology, Tshwane University of Technology, on 25 March 2019, who is the owner of the data within the university.

\section{Results \\ Self-perception accuracy}

In this study, self-perception accuracy was operationalised as congruence between self and direct reports' ratings of the participant's leadership behaviours. The Mann-Whitney test was performed to compare the self-rating and the rating given by observers for each of the four competence clusters. The test was performed for both genders. The Wilcoxon rank sum test or the Mann-Whitney $U$ test is the non-parametric equivalent of the independent $t$-test used to compare two independent conditions using ranks (Field, 2009, p. 540). According to Corder and Foreman (2009), the rank-based test also referred to as the Wilcoxon-Mann-Whitney test can be used to determine whether there are differences between two groups on a continuous or ordinal dependent variable. Managerial self-awareness was calculated using Pearson's Chi-square test of association, to discover if there is a relationship between two of the categorical variables, namely, Self and Other scores. As indicated in Table 1, males marginally overrated themselves on competence Cluster two and significantly overrated themselves on the competence 
TABLE 1: Wilcoxon-Mann-Whitney test - comparison of self-perception accuracy per gender for each of the four leadership clusters.

\begin{tabular}{|c|c|c|c|c|c|c|}
\hline \multirow[t]{2}{*}{ Leadership cluster } & \multicolumn{2}{|c|}{ Rank mean } & \multicolumn{2}{|c|}{$p$} & \multicolumn{2}{|c|}{$z$-score } \\
\hline & Female & Male & Female & Male & Female & Male \\
\hline \multicolumn{7}{|c|}{ Cluster one: collaborative change leadership } \\
\hline Observers & 310.37 & 483.64 & $0.014 *$ & $0.021 *$ & -2.458 & 2.299 \\
\hline Self & 276.16 & 525.52 & & & & \\
\hline \multicolumn{7}{|c|}{ Cluster two: strategy translation and innovation } \\
\hline Observers & 193.84 & 335.68 & 0.289 & 0.070 & -1.060 & 1.812 \\
\hline \multicolumn{7}{|c|}{ Cluster three: impactful relationships } \\
\hline Observers & 436.39 & 660.51 & $0.000 * *$ & $0.012 *$ & -4.328 & 2.503 \\
\hline Self & 365.91 & 713.75 & & & & \\
\hline \multicolumn{7}{|c|}{ Cluster four: disciplined results orientation } \\
\hline Observers & 308.24 & 478.67 & $0.0462 *$ & $0.013^{*}$ & -1.993 & 2.486 \\
\hline Self & 280.47 & 523.83 & & & & \\
\hline
\end{tabular}

Source: Saville Consulting (2015). Culture framework. Johannesburg: Saville Consulting (SA) Holdings. Retrieved from http://www.savilleconsulting.co.za/products/culture-framework $*, p<0.05 ; * *, p<0.01$.

clusters one, three and four. Women, on the other hand, marginally underrated themselves on competence Cluster two and significantly underrated themselves in the remaining three competence clusters.

\section{Comparison between men and women with regard to self-perception accuracy}

In this study, confidence was operationalised as selfperception accuracy, which implies congruence between self and direct reports' behavioural ratings of leadership behaviours. Self-perception accuracy was calculated using Pearson's Chi-square test of association, to discover if there is a relationship between the two categorical variables, namely, Self and Other scores.

From Table 1, it can be seen that there is a marginal difference between the self-rating and the rating given by observers in Cluster two and a significant difference in Cluster one $(z=2.458, p<0.05)$, Cluster three $(z=-4.328, p<0.01)$ and Cluster four $(z=-1.993, p<0.05)$. For women, the rank means indicate that the rating given by colleagues is significantly higher than the self-rating, which means that women significantly underrated themselves in three of the four clusters and marginally underrated themselves in Cluster two. The opposite is true for men who significantly overrated themselves in Cluster one $(z=2.299, p<0.05)$, Cluster three $(z=2.503, p<0.05)$ and Cluster four $(z=2.486, p<0.05)$. Thus, apart from Cluster two, in which men only marginally overrated themselves, for all the other clusters, men's own ratings are significantly higher than the ratings by their observers.

\section{Comparison between men and women regarding perceived leadership effectiveness}

To determine effectiveness, the 7-point Likert rating scale was divided into the following three categories:

- Development area:

- 1 = seldom effective

- 2 = sometimes effective

- 3 = adequately effective
- Effective:

- 4 = effective

- 5 = very effective

- Unusual strength:

- $6=$ often a strength

- $7=$ always a strength

The Chi-square test of independence was used to test the association between gender and the perceived effectiveness by others (the self-rating score was excluded) in the four leadership clusters. The proportions of men to the proportions of women in the different categories of effectiveness did not differ significantly in any of the 44 questions grouped into the four leadership competence clusters. Therefore, men and women did not differ with respect to their perceived leadership effectiveness.

\section{Discussion}

Although both men and women demonstrated low selfawareness (therefore exhibited low self-perception accuracy), the direction of the discrepancy in self-other ratings differed. The findings of this study confirm findings from previous studies (Moshavi et al., 2003; Niederle \& Vesterlund, 2007; Pulford \& Colman, 1997; Visser et al., 2008) that men in general tend to overestimate themselves as opposed to women who tend to either accurately estimate or underestimate their abilities (Betswood, 1999; Beyer, 1999). This is in line with earlier research studies (Taylor \& Hood, 2011; Wohlers \& London, 1989) that showed that women have a greater tendency to underrate their skills or performance in not taking credit for success and by attributing their success more to external sources than to ability. The finding by Taylor and Hood (2011, p. 640) that 'women were clearly not undervaluing themselves when they self-rated any more than men', a finding confirmed by other studies (Sturm, Taylor, Atwater, \& Braddy, 2014; Van Velsor et al., 1993), is therefore contradicted by the findings of this study.

The finding that women significantly underestimated themselves in three of the four clusters confirms the view by Chen and Moons (2015) that the perception that women lack 
interpersonal power in senior leadership roles might be one of the reasons why women are underrepresented in the senior management level. A possible explanation for their underrating in these clusters might be as a result of women often being told to tone down interpersonal behaviour. In addition, fear of receiving negative comments about their personality, if they behave assertively or come across as too powerful, might be a contributing factor (Rudman et al., 2012; Snyder, 2014). This tendency of women to underrate and underestimate themselves may perpetuate the current cycle of men being favoured for leadership positions and maintain the status quo regarding gender disparity in senior management levels.

Another possible explanation for women deflating their selfratings is that it might be a function of social-desirability or political factors (Braton, Dodd, \& Brown, 2011). That is, in an institution with a culture that discourages self-promotion amongst women (as women are still the minority in management positions in this university), it would be reasonable to expect that women managers would be more likely to distort their self-ratings in a downward direction. However, as emphasised by Atwater and Yammarino (1997), further research is needed to explore the reasons for gender differences in self-awareness.

Given the social sanctions that women experience for being assertive at work, training and development programmes to improve their self-confidence in this regard would not be sufficient. This confirms the view by Eagly (2005) that relying on training to address the gender gap defies simple prescriptions inherent in programmes such as assertiveness training. Leadership development interventions for women should rather focus on exploring the legitimacy deficit that women face when taking up a leadership role that are nontraditional for members of their group. Furthermore, the issue of effectively projecting the authority that comes with one's role should be addressed in development. This will enable women to 'lean in', take more risks and have more confidence in their own abilities to ultimately take action (Kay \& Shipman, 2014; Sandberg, 2013). For women, this might require unlearning some feminine behaviours moderating the women-stereotypical repertoire. This unlearning should be tempered with a clear understanding of the likely resistance to prominent displays of typical masculine behaviours. In this regard, Eagly (2005, p. 470) stated that 'adopting an identifiable masculine behavioural style may yield dislike'. The challenge therefore for women is to not only tone down their feminine style but also not to emulate male leaders. Furthermore, Beyer (1999) made an intriguing practical recommendation that women should be taught to be inaccurate - in essence, to overestimate themselves. She bases this view on various research studies (cited in Beyer 1999) that provide evidence for the link between self-enhancing biases (overestimation) and psychological health. This may result in improved motivation, task persistence and confidence in their future success.

However, women's missing agency is not in itself an adequateexplanation for theircontinued underrepresentation in senior and executive positions in HEIs (Burkinshaw \& White, 2017). Instead, as stated by Shepherd (2017), capable and ambitious women may be disadvantaged by a number of structural or social factors, for example, the recruitment and selection process for senior posts, paternalism, hostile cultures, stereotypes and homo-sociability or what Gallant (2014, p. 204) referred to as 'similarity attraction', leading to the appointment of 'more of the same' (Shephard, 2017, p. 86). This implies that efforts to 'fix' women, for example, women-only development programmes, such as the Higher Education Resource Services-South Africa (HERS-SA), ${ }^{3}$ Academy are unlikely to be sufficient to achieve gender equality. As stated by Fox (2013), this deficit or remedial approach to women's behaviour has helped to entrench rather than address the barriers women face and leaves many women perplexed, angry and demotivated. In this line, Ely et al. (2011) concurred and stated that this perspective on gender and leadership necessitates a new developmental approach to women in and aspiring to senior leadership positions.

Conversely, in line with the recommendation by Burkinshaw and White (2017), a mix of change interventions may be required that also seek to 'fix' universities, that is, in terms of systemic and procedural changes. More importantly, perhaps, the micro-politics, stereotypes, mindsets and cultural assumptions that underpin these practices and procedures (e.g. selection processes) also need to be acknowledged and addressed. In this regard, Martin and Phillips (2017) found that 'gender blindness' is a more adaptive strategy for increasing women's workplace confidence than genderawareness and highlights the potential for downplaying differences, instead of emphasising them, to combat the confidence gap. However, Manfredi (2017) disagrees and recommends that claims of 'gender blindness' universities use to demonstrate their commitment to equality should be replaced with 'gender consciousness'. The shift from 'blindness' to 'consciousness' will take candidates' identity into account in selection and development processes. This would imply that instead of appointing candidates who look like the 'familiar type' of leader in a male-dominated culture, the appointment of more women in executive positions would establish a 'virtuous circle' by creating a critical mass of women leaders for change. As eluded to by Howe-Walsh and Turnbull (2016), these women role models would encourage other women to aspire to senior-level positions. Appelbaum, Audet and Joanne (2003) echoed the opinion that the current evaluative norms that reward masculinity will only change once a significant number of women move into senior and executive management. As stated by White et al. (2011), it takes courage and resilience for a woman to apply for a senior management position in a masculine organisational culture. The women that formed part of this study were already in middle and senior academic management positions and may thus not be typical of the wider women in the academia cohort.

3.Higher Education Resource Services-South Africa (HERS-SA) is a non-profit organisation dedicated to the advancement and leadership development of women in the HE sector. dedicated to the advancement and leadership development of women in the HE sector.
Their annual academy is week-long interactive professional development opportunity Their annual academy is week-long interactive professional development
aimed at empowering women to take up leadership positions in HEls in SA. 


\section{Limitations and future research}

The results of the study need to be considered within the context of possible limitations. The relatively small sample size precludes generalisability of the findings, and the author suggests that future research incorporates a larger scale and more diverse samples inclusive of other universities nationally and internationally to confirm the findings of the current study. In addition, further investigation is required to explore the most effective strategy to enhance the selfconfidence of women.

\section{Conclusion}

This article set out to extend understanding of the barriers that challenge women in reaching senior positions within HEIs. Previous sources (Bear et al., 2017; Kay \& Shipman, 2014; Manfredi et al., 2014) have cited lack of selfconfidenceas an explanation for women's continued underrepresentation in senior leadership positions. Solving the gender gap is a complex multi-faceted issue requiring an equally multi-faceted approach. However, the study has added empirical evidence that women, in comparison to men, still underestimate themselves in spite of being perceived as equally effective leaders. This reveals the importance of emboldening women to back themselves more and doubt themselves less. There is no quick fix for building self-confidence or permanently eradicating selfdoubt in women. The author agrees with Martin and Phillips (2017) who cautioned against adopting universal strategies for approaching diversity and advocated for more tailored solutions to address the context and needs of each social group. However, as mentioned by various authors (Burkinshaw \& White, 2017; Kayi, 2013; Ragins et al., 1998; Toni \& Moodly, 2019), the key underlying factor behind the effective implementation of all other interventions (e.g. diversity training, cross-gender mentoring, inclusion of gender and diversity issues in executive education, flexible work place policies) is top management commitment. In this regard, they state that raising the consciousness of the chief executive officer (in the case of universities the vice chancellor) and senior management to be an active voice for institutional change at the highest level is the need of the hour.

\section{Acknowledgements}

The author would like to thank Princess Ramokolo for the statistical analysis, the Tshwane University of Technology (TUT) management for their support and the respondents for taking part in the research.

\section{Competing interests}

The author has declared that no competing interest exists.

\section{Author's contributions}

The author declares that she is the sole author of this article.

\section{Funding information}

The project was funded by the Department of Higher Education and Training (DHET) Teaching Development Grant (TDG).

\section{Data availability statement}

Data sharing is not applicable to this article as no new data were created or analysed in this study.

\section{Disclaimer}

The views and opinions expressed in this article are those of the author and do not necessarily reflect the official policy or position of any affiliated agency of the author.

\section{References}

Acker, S. (2010). Gendered games in academic leadership. International Studies in Sociology of Education, 20(2), 129-152. https://doi.org/10.1080/09620214.2010. 503062

Anderson, C., \& Brion, S. (2010). Overconfidence and the attainment of power. Unpublished manuscript. Berkeley: University of California. Retrieved from https://www8.gsb.columbia.edu/rtfiles/management/anderson\%26brion.pdf

Appelbaum, S.H., Audet, L., \& Joanne C.J.C. (2003). Gender and leadership? Leadership and gender? A journey through the landscape of theories. Leadership \& Organization Development Journal, 24(1), 43-51. https://doi.org/10.1108/01437730310457320

Atwater, L., \& Yammarino, F.J. (1997). Self-other rating agreement: A review and model. Research in Personnel and Human Resources Management, 15, 121-174.

Bandura, A. (1997). Self-efficacy: The exercise of control. New York: Freeman.

Barber, B.M., \& Odean, T. (2001). Boys will be boys: Gender, overconfidence, and common stock investment. The Quarterly Journal of Economics, 116(1), 261-292.

Bear, B.B., Cushenbery, L., London, M., \& Sherman, G.D. (2017). Performance feedback, power retention, and the gender gap in leadership. Leadership Quarterly, 28(6), 721-740. https://doi.org/10.1016/j.Jeaqua.2017.02.003

Betswood, D.G. (1999). Accuracy of self-estimated abilities and the relationship between self-estimated abilities and realism for women. Journal of Career Assessment, 7(1), 35-43. https://doi.org/10.1177/106907279900700103

Beyer, S. (1999). Gender differences in the accuracy of self-evaluation of performance. Journal of Personality and Social Psychology, 59(5), 960-970. https://doi. org/10.1037/0022-3514.59.5.960

Booysen, L., \& Nkomo, S. (2010). Gender role stereotypes and requisite management characteristics: The case of South Africa. Gender in Management: An International Journal, 25(4), 285-300. https://doi.org/10.1108/17542411011048164

Bratton, V.K., Dodd, N.G., \& Brown, F.W. (2011). The impact of emotional intelligence on accuracy of selfawareness and leadership performance. Leadership \& Organization Development Journal, 32(2), 127-149. https://doi.org/10.1108/01437731111112971

Burkinshaw, P., \& White, K. (2017). Fixing the women or fixing universities: Women in HE leadership. Administrative Sciences, 7(3), 30. https://doi.org/10.3390/admsci7030030

Business Women's Association of South Africa (2017). Women in leadership census. Retrieved from https://bwasa.co.za/wp-content/uploads/2018/04/2017 BWASA-CENSUS-report.pdf

Carducci, B.C. (2009). The psychology of personality: Viewpoints, research and applications (2nd edn.). West-Sussex: Wiley-Blackwell.

Chen, J.M., \& Moons, W.G. (2015). They won't listen to me: Anticipated power and women's disinterest in male-dominated domains. Group Processes \& Intergroup Relations, 8(1), 116-128. https://doi:10.1177/1368430214550340

Corder, G.W., \& Foreman, D.I. (2009). Nonparametric statistics for non-statisticians: A step-by-step approach. Hoboken, NJ: John Wiley \& Sons, Inc. Retrieved from https://doi.org/10.1002/9781118165881

Croson, R., \& Gneezy, U. (2009). Gender differences in preferences. Journal of Economic Literature, 47(2), 448-474. https://doi.org/10.1257/jel.47.2.448

Cuddy, A.J., Glick, P., \& Beninger, A. (2011). The dynamics of warmth and competence judgments, and their outcomes in organizations. Research in Organizational Behavior, 31, 73-98. https://doi.org/10.1016/j.riob.2011.10.004

Damaske, S. (2011). A 'major career woman?' How women develop early expectations about work. Gender and Society, 25(4), 409-430. https://doi. org/10.1177/0891243211412050

Damian, D., \& Pitts, S. (2015). Go slow to go fast - planning to execution. New York: Morgan James Publishing.

Devar, D. (2017). An analysis of the attraction and retention of women in higher education institutions: A case study of the University of Pretoria and the University of Kwa-Zulu- Natal. (Master's dissertation), Retrieved from https://repository. up.ac.za/bitstream/handle/2263/60533/Devar_Analysis_2017.pdf?sequence= 1 \&isAllowed=y 
Eagly, A.H., \& Carli, L.L. (2003). The female leadership advantage: An evaluation of the evidence. The Leadership Quarterly, 14(6), 807-834. https://doi.org/10.1016/j. leaqua.2003.09.004

Eagly, A.H. (2005). Achieving relational authenticity in leadership: Does gender matter? The Leadership Quarterly, 16(3), 459-474. https://doi.org/10.1016/j. leaqua.2005.03.007

Ely, R.J., Ibarra, H., \& Kolb, D.M. (2011). Taking gender into account: Theory and design for women's leadership development programs. Academy of Management
Learning \& Education, 10(3), 474-493. https://doi.org/10.5465/amle.2010.0046

Field, A. (2009). Discovering statistics using SPSS (3rd edn.). London: Sage Publications Ltd.

Fleenor, J.W., Smither, J.W., Atwater, L.E., Braddy, P.W., \& Sturm, R.E. (2010). Self-other rating agreement in leadership: A review. Leadership Quarterly, 21(6), 1005-1034. https://doi.org/10.1016/j.leaqua.2010.10.006

Fox, C. (2013). The higher you go, the wider the gap. In: CEDA (Ed.), Women in Leadership: Understanding the gender gap (pp. 21-32). Melbourne: CEDA.

Gallant, A. (2014). Symbolic interactions and the development of women leaders in higher education. Gender, Work and Organization, 21(3), 203-216.

Gosling, S.D., Bleidorn, W., Denisen, J.J.A., Gebauer, J.E., Arslan, R.C., Rentfrow, P.J., \& Potter, J. (2016). Age and gender differences in self-esteem: A cross-cultura window. Journal of Personality and Social Psychology, 111(3), 396-410. https:// doi10.1037/pspp0000078

Heilman, M., \& Okimoto, T. (2007). Why are women penalized for success at male tasks?: The implied communality deficit. Journal of Applied Psychology, 92(1), 81-92. https://doi.org/10.1037/0021-9010.92.1.81

Heilman, M.E., \& Parks-Stamm, E.J. (2007). Gender stereotypes in the workplace: Obstacles to women's career progress. In S.J. Correll (Ed.), Social psychology of gender: Advances in group processes (pp. 47-77). Greenwich: JAI Press.

Howe-Walsh, L., \& Turnbull, S. (2016). Barriers to women leaders in academia: Tales from science and technology. Studies in Higher Education, 41(3), 415-428. https://doi 10.1080/03075079.2014.929102

Hoyt, C.L., \& Murphy, S.E. (2016). Managing to clear the air: Stereotype threat women, and leadership. The Leadership Quarterly, 27(3), 387-399. https://doi. org/10.1016/j.leaqua.2015.11.002

Kark, R., Waismel-Manor, R., \& Shamir, B. (2012). Does valuing androgyny and femininity lead to a female advantage? The relationship between gender-role, transformational leadership and identification. The Leadership Quarterly, 23(3), 620-640. https://doi.org/10.1016/j.leaqua.2011.12.012

Kay, K., \& Shipman, C. (2014). The confidence code: The science and art of self-assurance - what women should do. New York: Harper-Collins Publishers.

Kayi, N. (2013). The progression of women to senior management positions at a South African university in the Western Cape. (Master's Dissertation), Retrieved from http://etd.cput.ac.za/bitstream/handle/20.500.11838/1018/30007300_Kayi N MTech_bus_admin_2013.pdf?sequence $=4 \&$ is Allowed $=y$

Kele, T., \& Pietersen, J. (2015). Women leaders in a South African higher education institution: Narrations of their leadership operations. OIDA International Journa of Sustainable Development, 8(5), 11-16.

Kets de Vries, M.F.R., \& Korotov, K. (2010). Transformational Leadership Development Programs: Creating Long-Term Sustainable Change. INSEAD Working Paper No. 2010/72/EFE/IGLC. Retrieved from https://ssrn.com/abstract=1680753

Kinnear, L., \& Ortlepp, K. (2016). Emerging models of power among South African women business leaders. SA Journal of Industrial Psychology/SA Tydskrif vir Bedryfsielkunde, 42(1), a1359. https://doi.org/10.4102/sajip.v42i1.1359

Koenig, A., Eagly, A., Mitchell, A., \& Ristikari, T. (2011). Are leader stereotypes masculine? A meta-analysis of three research paradigms. Psychological Bulletin, masculine? A meta-analysis of three research parad
137(4), 616-642. https://doi.org/10.1037/a0023557

Lyness, K.S., \& Heilman, M.E. (2006). When fit is fundamental: Performance evaluation and promotions of upper-level female and male managers. Journal of Applied Psychology, 91(4), 777-785. https://doi.org/10.1037/0021-9010.91.4.777

Manfredi, S., Grisoni, L., Handley, K., Nestor, R., \& Cooke, F. (2014). Gender and higher education leadership: Researching the careers of top management programme alumni. London: Leadership Foundation for Higher Education

Manfredi, S. (2017). Increasing gender diversity in senior roles in HE: Who is afraid of positive action? Administrative Sciences, 7(2), 19. https://doi:10.3390/admsci7020019

Martin, A.E., \& Phillips, K.W. (2017). What 'blindness' to gender differences helps women see and do: Implications for confidence, agency, and action in maledominated environments. Organizational Behavior and Human Decision Processes, 142(C), 28-44. https://doi: 10.1016/j.obhdp.2017.07.004

McCormick, M.J. (2001). Self-efficacy and leadership effectiveness: Applying social cognitive theory to leadership. The Journal of Leadership Studies, 8(1), 22-33. Retrievedfromhttps://journals.sagepub.com/doi/pdf/10.1177/107179190100800102

McGlone, M.S., \& Pfeister, R.A. (2015). Stereotype threat and the evaluative context of communication. Journal of Language and Social Psychology, 34(2), 111-137. https://doi.org/10.1177/0261927X14562609

Meyerson, S.L., Sternbach, J.M., Zwischenberger, J.B., \& Bender, E.M. (2017) The effect of gender on resident autonomy in the operating room. Journal of Surgical Education, 74(6), 111-118. https://doi.org/10.1016/j.jsurg.2017.06.014

Moodly, A.L., \& Toni, N. (2015). Women's access towards higher education leadership: Where are the role models? Journal of Social Sciences, 45(1), 45-52. https://doi. org/10.1080/09718923.2015.11893486

Moodly, A.L., \& Toni, N.M. (2017). Gender equity in South African higher education leadership: Where are we twenty years after democracy? South African Journal of Higher Education, 31(3), 138-153. https://doi.org/10.20853/31-3-917
Moore, D. A., \& Healy, P. J. (2008). The trouble with overconfidence. Psychological Review, 115, 502-517.

Morley, L. (2013). The rules of the game: Women and the leaderist turn in higher education. Gender and Education, 25(1), 116-131. https://doi.org/10.1080/0954 0253.2012.740888

Moshavi, D., Brown, F.W., \& Dodd, N.G. (2003). Leader self-awareness and its relationship to subordinate attitudes and performance. Leadership and Organizational Development Journal, 24(7), 407-418. https://doi.org/10.1108/ 01437730310498622

Mouton, J., \& Marais, H.C. (1989). Metodologie van die Geesteswetenskalike: Basiese begrippe. Pretoria: Raad vir Geestewetenskaplike Navorsing.

Naidu, E. (2018, July). Universities body to probe gender imbalance at the top. University world news. Retrieved from https://www.universityworldnews.com/ post.php?story $=20180725103923330$

Niederle, M., \& Vesterlund, L. (2007). Do women shy away from competition? Do men compete too much? The Quarterly Journal of Economics, 122(3), 1067-1101. https://doi.org/10.1162/qjec.122.3.1067

Pulford, B. D., \& Colman, A. M. (1997). Overconfidence: Feedback and item difficulty effects. Personality and Individual Differences, 23, 125-133.

Ragins, B.R., Townsend, B., \& Mattis, M. (1998). Gender gap in the executive suite: CEOs and female executives report on breaking the glass ceiling. Academy of Management Executive, 12(1), 28-42. https://doi.org/10.5465/ame.1998.254976

Reuben, E., Rey-Biel, P., Sapienza, P., \& Zingales, L. (2012). The emergence of male leadership in competitive environments. Journal of Economic Behavior and Organization, 83, 111-117.

Rudman, L.A., Moss-Racusin, C.A., Phelan, J.E., \& Nauts, S. (2012). Status incongruity and backlash effects: Defending the gender hierarchy motivates prejudice against female leaders. Journal of Experimental Social Psychology, 48(1), 165-179. https://doi:10.1016/j.jesp.2011.10.008

Sandberg, S. (2013). Lean in: Women, work, and the will to lead. New York, NY: Knoph.

Saville Consulting (2015). Culture framework. Johannesburg: Saville Consulting (SA) Holdings. Retrieved from http://www.savilleconsulting.co.za/products/cultureframework

Shepherd, S. (2017). Why are there so few female leaders in higher education: A case of structure or agency? Management in Education, 31(2), 82-87. https://doi. org/10.1177/0892020617696631

Shrauger, J.S., \& Schohn, M. (1995). Self-confidence in college students: Conceptualization, measurement and behavioural implications. Psychological Assessment Resources, 2(3), 255-278. https://doi.org/10.1177/1073191195002003006

Snyder, K. (2014). The abrasiveness trap: High-achieving men and women are described differently in reviews. Fortune, August 26. Retrieved from https://fortune.co/2014/08/26/performance-review-gender-bias/

Stainback, K., Kleiner, S., \& Skaggs, S. (2016). Women in power: Undoing or redoing the gendered organization? Gender and Society, 30(1), 109-135. https://doi.org/10.1177/0891243215602906

Stead, V. (2014). The gendered power relations of action learning: A critical analysis of women's reflections on a leadership development programme. Human Resource Development International, 17(4), 416-437. https://doi.org/10.1080/13678868.2 014.928137

Sturm, R.E., Taylor, S.N., Atwater, L.E., \& Braddy, P.W. (2014). Leader self-awareness: An examination and implications for women leaders. Journal of Organizationa Behavior, 35, 657-677.

Taylor, S.N., \& Hood, J.N. (2011). It may not be what you think: Gender differences in predicting emotional and social competence. Human Relations, 64, 627-652.

Toni, N.M., \& Moodly, A.L. (2019). Do institutional cultures serve as impediments for women's advancement towards leadership in South African higher education? South African Journal of Higher Education, 33(3), 176-191. https://doi.org/10.20853/33-3-3137

Van Velsor, E., Taylor, S., \& Leslie, J. (1993). An examination of the relationships among self-perception accuracy, self-awareness, gender and leader effectiveness. Human Resource Management, 32(2/3), 249-264.

Visser, B.A., Ashton, M.C., \& Vernon, P.A. (2008). What makes you think you're so smart? Measured abilities, personality, and sex differences in relation to selfestimates of multiple intelligences. Journal of Individual Differences, 29, 35-44.

White K., Carvalho, T., \& Riordan, S. (2011). Gender, power and managerialism in universities. Journal of Higher Education Policy and Management, 33(2), 179-188.

Williams, M.J., \& Tiedens, L.Z. (2015). The subtle suspension of backlash: A metaanalysis of penalties for women's implicit and explicit dominance behavior. Psychological Bulletin, 142(2), 165-197. https://doi.org/10.1037/bul0000039

Winchester, H.P.N., \& Browning, L. (2015). Gender equality in academia: A critical reflection. Journal of Higher Education Policy and Management, 37(3), 269-281. heflection. Journal of Higher Education Policy and

Wohlers, A.J., Hall, M.J., \& London, M. (1993). Subordinates rating managers: Organizational and demographic correlates of self/subordinate agreement. Journal of Occupational and Organizational Psychology, 66, 263-275. https://doi. org/10.1111/j.2044-8325.1993.tb00538.x

World Economic Forum (WEF) (2017). The global gender gap report [online]. Geneva: World Economic Forum. Retrieved from https://www3.weforum.org/ docs/WEF_GGGR_2017.pdf

Yammarino, F.J., \& Atwater, L.E. (1993). Understanding self-perception accuracy: Implications for human resource management. Human Resource Management, 32, 231-247. https://doi.org/10.1002/hrm.3930320204 